\title{
Heterogeneous HBV mutants coexist in Korean hepatitis B patients
}

\author{
Won Kyoung Keum, ${ }^{1,4}$ Jee Youn Kim, ${ }^{1}$ \\ Ja Young Kim, ${ }^{1}$ Sung Gil Chi, ${ }^{2}$ \\ Hong Jung Woo, ${ }^{3,4}$ Sung Soo Kim, ${ }^{1,4}$ \\ Joohun $\mathrm{Ha}^{1,4}$ and Insug Kang ${ }^{1,4,5}$ \\ 1 Department of Molecular Biology, School of Medicine, \\ Kyung Hee University, Seoul 130-701, Korea \\ 2 Department of Pathology, School of Medicine, Kyung Hee University, \\ Seoul 130-701, Korea \\ 3 Department of Internal Medicine, School of Oriental Medicine, \\ Kyung Hee University, Seoul 130-701, Korea \\ 4 East-West Medical Research Institute, Kyung Hee University, \\ Seoul 130-701, Korea \\ 5 Corresponding Author \\ Accepted 5 June 1998
}

Abbreviations: HBV, hepatitis B virus; HBeAg, hepatitis B e antigen; HBsAg, hepatitis B surface antigen; anti-HBe, antibody to HBeAg; PCR-SSCP, polymerase chain reactionsingle strand conformation polymorphism; ALT, alanine aminotransferase; AST, aspartate aminotransferase

\begin{abstract}
Although many hepatitis B virus (HBV) mutants have been found in all open reading frames since the precore defective mutant was initially reported, systematic investigations of diverse HBV mutant populations in hepatitis $B$ patients have not been performed. Therefore, we examined whether heterogeneous mutant populations simultaneously exist in Korean hepatitis B patients. In order to detect hepatitis $B$ virus mutants, we amplified a conserved core region and a surface antigen region of $\mathrm{HBV}$ DNA by PCR from sera of 27 Korean chronic hepatitis $B$ patients, and then performed single strand confor-mational polymorphism analysis followed by DNA sequencing analysis. The results showed that heterogeneous HBV mutants in both regions were present in a single as well as in various hepatitis $B$ patients. Sequence analysis revealed a defective interfering particle with missense mutation in the core region. We also found that two subtypes of adr and adw coexisted in a single patient. In addition, a point mutation causing a stop codon in the surface antigen region was observed. We are further analyzing the clinical implications of HBV mutants to identify their roles
\end{abstract}

in the pathogenesis of chronic hepatic disorders induced by HBV.

Keywords: HBV DNA, HBV mutant, PCR-SSCP

\section{Introduction}

Hepatitis B virus (HBV) is a small circular, partially doublestranded DNA virus (3.2 kb) and requires reverse transcription of pregenomic RNA during replication (Summers and Mason, 1982). This reverse transcription accounts for the greater genetic variability of HBV genome in comparison with other DNA viruses (Will et al., 1987).

Since PCR was used for detection of HBV DNA, many HBV mutants have been reported. The first identified precore defective mutant was found in the patient whose $\mathrm{HBeAg}$ was seroconverted to negative (Carman et al., 1989). Thereafter, many HBV mutants in surface antigen, core and polymerase regions as well as precore region have been observed in persistently infected hosts (Blum et al., 1991; Ackrill et al., 1993; Carman et al., 1993; Hasegawa et al., 1994; Miska et al., 1994; Wallace et al., 1994). One of the well characterized mutants is precore mutant which does not encode e antigen because of the nonsense mutation created in the upstream of the start codon of core antigen (Ulrich et al., 1990). Thus, patients infected by these precore mutants showed negative results in $\mathrm{HBeAg}$ test providing incorrect informations about the progression of hepatitis in hepatitis $B$ patients because seroconversion of $\mathrm{HBeAg}(+)$ to $\mathrm{HBeAg}(-) / a n t i-$ $\mathrm{HBe}(+)$ was interpreted as an indicator of a favorable prognosis (Fiordalisi et al., 1990; Nordenfelt et al., 1995).

Several HBV variants with mutations in determinant sites of surface antigen region were identified from patients in whom the HBV vaccine had failed to provide protection (Karthigesu et al., 1994; Hawkins et al., 1996; Chiou et al., 1997). Precore/core and presurface HBV mutants were shown to emerge spontaneously during the natural course of chronic infection, during interferon therapy or in immunosupressed patients (Blum, 1993). The importance of HBV mutants in pathogenicity, immunity, progression, and responsiveness to treatment has emerged as an area for intensive study. However, systematic investigations of diverse HBV mutant populations in hepatitis $B$ patients have not been performed. Instead, most studies were focused on specific mutant types. Therefore, we systematically attempted to investigate HBV mutants in chronic hepatitis $B$ patients in Korea. In order to do this, we amplified a conserved core region as well as surface 
antigen region of HBV DNA by PCR, performed SSCP analysis, and then analyzed DNA sequence. The results show that the heterogeneous HBV mutant populations exist simultaneously in Korean chronic hepatitis $B$ patients. We are investigating the potential clinical implications of mutant forms of HBV DNA.

\section{Materials and Methods}

\section{Patient serum}

Serum specimen were obtained from patients at Kyung Hee University Hospital of Oriental Medicine. All patients were HBsAg (+). The informed consent was obtained from each patient. Serological tests for $\mathrm{HBsAg} /$ anti-HBs, $\mathrm{HBeAg} / \mathrm{anti}-\mathrm{HBe}$ and anti-HBc were performed with radioimmunoassays using the commercially available kits (Abbott Laboratories).

\section{Oligonucleotide primers}

Primers for PCR amplification were designed in the conservative core regions to avoid mismatch as follows. The forward primer of set 1,5'-TTCTTAGGGGCATGGACA
TTGA-3', begins at map position 1776 and its backward primer, 5'-AATTCCCTGGATGCTGGGTC-3', begins at map position 2025. The forward primer of set 2, 5'-CATTGAC CCGTATAAAGAATT-3', begins at map position 1779 and its backward primer, 5'-TCCCTGGATGCTGGGTCTTCCAA A-3', begins at map position 2022 . To amplify various regions in the whole HBV genomic DNA, 15 oligonucleotide primer sets were designed as shown in Table 1.

\section{PCR amplification of HBV DNA extracted from virion in serum}

HBV DNA was extracted using $\mathrm{NaOH}$ method as described by Kaneko et al. (1990). PCR amplification of HBV DNA was performed as described by Keum et al. (1997). To avoid contamination from floating amplicon in the air, PCR mixture containing $1 \times$ buffer, $\mathrm{MgCl}_{2}$, dNTP and primers were prepared and then 8-methoxypsoralen was added to the reaction mixture to give a final concentration of $10 \mu \mathrm{g} / \mathrm{ml}$. After this PCR mixture was exposed to UV light for $10 \mathrm{~min}$ at room temperature, Taq polymerase and template were added. One picogram of pGEM-HBV vector DNA was subjected to PCR as a positive control.

Table 1. The primer sets used for the amplification of whole HBV genome.

\begin{tabular}{|c|c|c|c|}
\hline \multicolumn{4}{|c|}{ I. S site (pre S1, pre S2, S) 2722-3215, 1-709 } \\
\hline & $+(\rightarrow)$ & & $-(\leftarrow)$ \\
\hline & 5'- & & $5^{\prime}-$ \\
\hline S 2657 & 2657 agagaaactacacgcagcgc & S 2950 & 2950 accccaaaagaccgccgtgt \\
\hline S 2905 & 2905 gagacttcgggccagggttc & S 3110 & 3110 gcttggtggaatgttgtgga \\
\hline S 3066 & 3066 tcatcctcaggccatgcagt & S 40 & 40 tgtgctctccatgttcggtg \\
\hline S 20 & 20 caccgaacatggagagcaca & S 260 & 260 gcagacacatccagcgatag \\
\hline S 241 & 241 ctatcgctggatgtgtctgc & S 460 & 460 gtccgaaggttttgtacacc \\
\hline S 408 & 408 ctgctcaaggaacctctatg & S 650 & 650 tgttgtacagacttggccсc \\
\hline S 631 & 631 ggggccaagtctgtacaaca & S 906 & 1906 tgtaaaaggggcagcaaagc \\
\hline \multicolumn{4}{|c|}{ II. la site $710-1247$} \\
\hline la 887 & 887 gctttgctgccccttttaca & la 1260 & 1260 cccgagcagccatgggaagg \\
\hline \multicolumn{4}{|c|}{ III. $X$ site $1248-1712$} \\
\hline$X 1131$ & 1131 tctgccgatccatactgcgg & X 1520 & 1520 cttaggcaagacctggtggg \\
\hline XP 1481 & 1481 catggagaccaccgtgaacg & $\times 1776$ & 1776 atgccccaaagccacccaag \\
\hline \multicolumn{4}{|c|}{ IV. C site (pre C, C) 1688-2326 } \\
\hline Pre C 1643 & 1643 tgtactaggaggctgtaggc & C 1960 & 1960 ccaacacaggatagcttgcc \\
\hline C 1941 & 1941 ggcaagctatcctgtgttgg & C 2180 & 2190 ataggggcatttggtggtct \\
\hline C Pol 2171 & 2171 agaccaccaaatgcccctat & C 2340 & 2340 gagtccaagggatactaaca \\
\hline \multicolumn{4}{|c|}{ V. Ib site $2327-2721$} \\
\hline Ib 2321 & 2321 tgttagtatcccttggactc & Ib 2530 & 2530 ggatagaacctagcaggcat \\
\hline Ib 2511 & 2511 atgcctgctaggttctatcc & Ib 2722 & 2722 tgctgtagctcttgttccca \\
\hline
\end{tabular}




\section{Nonisotopic DNA/PCR-SSCP analysis}

Nonisotopic PCR-SSCP analysis was performed as previously described by Chi et al. (1994). Briefly, the extracted DNA from sera of 25 chronic hepatitis $B$ patients was subjected to PCR for amplification of the conserved core region of HBV DNA using oligonucleotide primers described above, and then $20 \mu \mathrm{l}$ of PCR products were mixed with $7 \mu \mathrm{l}$ of alkaline solution and $15 \mu \mathrm{l}$ of denaturing loading buffer. Total volume was adjusted to $45 \mu \mathrm{l}$ by adding $\mathrm{H}_{2} \mathrm{O}$. After heating at $95^{\circ} \mathrm{C}$ for 5 min, each sample was rapidly loaded onto an $8 \%$ or $10 \%$ nondenaturing polyacrylamide gel in $0.5 \times$ TBE buffer. The upper chamber was pre-cooled at $4^{\circ} \mathrm{C}$ with buffered ice before the samples were loaded. Each sample was applied to two gels with and without $5 \%$ glycerol, and the gels were run at $18-20^{\circ} \mathrm{C}$, and $6-8^{\circ} \mathrm{C}$. Therefore, each PCR product was applied to gel electrophoresis under four different conditions. Following a 3-5 h run at 450 volts, the gel was stained with ethidium bromide for 5 min and destained with $\mathrm{H}_{2} \mathrm{O}$ and photographed under ultraviolet light.

\section{Subcloning and sequencing of HBV PCR products}

The amplified region of HBV DNA from a single patient showing multiple migration shifts on SSCP analysis were ligated into the TA cloning vector (Invitrogen). The resulting plasmids were then used to transform Escherichia coli cells INV F'(Invitrogen). The multiple colonies were selected and the inserted HBV DNA sequences were amplified using the HBV DNA region-specific primers. After confirmation of migration shifts of these cloned PCR products using SSCP analysis, the representative clones were subjected to sequencing analysis. We used the same protocol for generating single-stranded templates for subsequent sequencing as the previously reported (Saunders et al., 1992). All specimens were sequenced in both directions to confirm the findings.

\section{Results and Discussion}

\section{SSCP analysis of core region of HBV DNA in chronic hepatitis $B$ patients}

It is believed that certain amino acid changes in core protein may abolish the effectiveness of the T- and B-cell responses in controlling HBV infection, thereby allowing recurrent viraemia (Chisari and Ferrari, 1995). Although the presence of quasi-species was reported in an anti$\mathrm{HBe}(+)$ patient infected with precore mutant virus (Alexopoulou et al., 1997), the presence of a mixture of core variants in a serum and the extent of their variation in chronic HBV infection has not been fully investigated in Korean hepatitis $B$ patients. Therefore, we attempted to find HBV core mutants by PCR after amplification of HBV DNA in sera of 25 chronic hepatitis B patients (Table
2). PCR products amplified from 25 patients showed a whole variety of DNA bands after single strand conformational polymorphism (SSCP) (Figure 1). Multiple bands shown in each lane suggest that heterogeneous HBV mutants are present in a single patient. The difference in band intensities further suggests that certain types of mutants prevail dominantly over the other types. To confirm our SSCP findings that multiple mutants coexist in a single patient, we transformed Escherichia coli with HBV DNA amplified from patient 3 in Table 2 (lane 3 in Figure 1). After reamplification of HBV DNA isolated from 40 transformed colonies by the same primer set, we performed SSCP again. The results of this second SSCP revealed that at least 7 different mutant types were indeed present in this patient (Figure 2). The second PCR-SSCP analysis revealed that some mutants were actually more frequently found. These findings further suggest that certain mutant types prevail dominantly.

Table 2. Serologic and laboratory data of 27 Korean chronic hepatitis $B$ patients at the time of study. Seventeen patients are $\mathrm{HBeAg}(+)$ and 10 patients are anti-HBe $(+)$

\begin{tabular}{|c|c|c|c|c|c|}
\hline $\begin{array}{l}\text { Patient } \\
\text { number }\end{array}$ & Age/Sex & $\mathrm{HBsAg}$ & $\begin{array}{c}\mathrm{HBeAg} / \\
\text { anti-HBe }\end{array}$ & $\begin{array}{c}\text { ALT/AST } \\
(I U / I)\end{array}$ & $\begin{array}{c}\text { HBV strain } \\
\text { subtype }\end{array}$ \\
\hline 1 & $40 / \mathrm{M}$ & + & $-/+$ & $46 / 37$ & $a d r$ \\
\hline 2 & $35 / \mathrm{M}$ & + & $-/+$ & $47 / 40$ & $a d r$ \\
\hline 3 & $35 / \mathrm{M}$ & + & $-/+$ & $109 / 46$ & $a d r$ \\
\hline 4 & $32 / \mathrm{M}$ & + & $-/+$ & $24 / 20$ & $a d r$ \\
\hline 5 & 41/M & + & $-/+$ & $38 / 25$ & $a d r$ \\
\hline 6 & $36 / \mathrm{M}$ & + & $-/+$ & $51 / 32$ & $a d r$ \\
\hline 7 & $39 / F$ & + & $-/+$ & $99 / 63$ & $a d r$ \\
\hline 8 & $31 / F$ & + & $-/+$ & $22 / 19$ & $a d r$ \\
\hline 9 & $36 / \mathrm{M}$ & + & $-/+$ & $51 / 32$ & $a d r$ \\
\hline 10 & $28 / \mathrm{M}$ & + & $+/-$ & $103 / 54$ & $a d r$ \\
\hline 11 & $38 / \mathrm{M}$ & + & $+/-$ & $43 / 28$ & $a d r$ \\
\hline 12 & $42 / M$ & + & $+/-$ & $21 / 19$ & $a d r$ \\
\hline 13 & $44 / \mathrm{M}$ & + & $+/-$ & $88 / 40$ & $a d r$ \\
\hline 14 & 41/M & + & $+/-$ & $47 / 42$ & $a d r$ \\
\hline 15 & $38 / \mathrm{M}$ & + & $+/-$ & $45 / 24$ & $a d r$ \\
\hline 16 & $32 / \mathrm{M}$ & + & $+/-$ & $112 / 44$ & $a d r$ \\
\hline 17 & $23 / F$ & + & $+/-$ & $269 / 184$ & $a d r$ \\
\hline 18 & $41 / \mathrm{M}$ & + & $+/-$ & $114 / 71$ & $a d r$ \\
\hline 19 & $45 / F$ & + & $+/-$ & $148 / 59$ & $a d r$ \\
\hline 20 & $34 / F$ & + & $+/-$ & $139 / 80$ & $a d r$ \\
\hline 21 & $43 / \mathrm{M}$ & + & $+/-$ & $85 / 60$ & $a d r$ \\
\hline 22 & $29 / F$ & + & $+/-$ & $46 / 50$ & $a d r$ \\
\hline 23 & $48 / F$ & + & $+/-$ & $98 / 79$ & $a d r$ \\
\hline 24 & $45 / \mathrm{M}$ & + & $+/-$ & $35 / 53$ & $a d r$ \\
\hline 25 & $44 / F$ & + & $+/-$ & $21 / 26$ & $a d r$ \\
\hline 26 & $40 / F$ & + & $-/+$ & $145 / 88$ & $a d r$ \\
\hline 27 & $53 / \mathrm{M}$ & + & $+/-$ & $61 / 83$ & $a d r$ \\
\hline
\end{tabular}




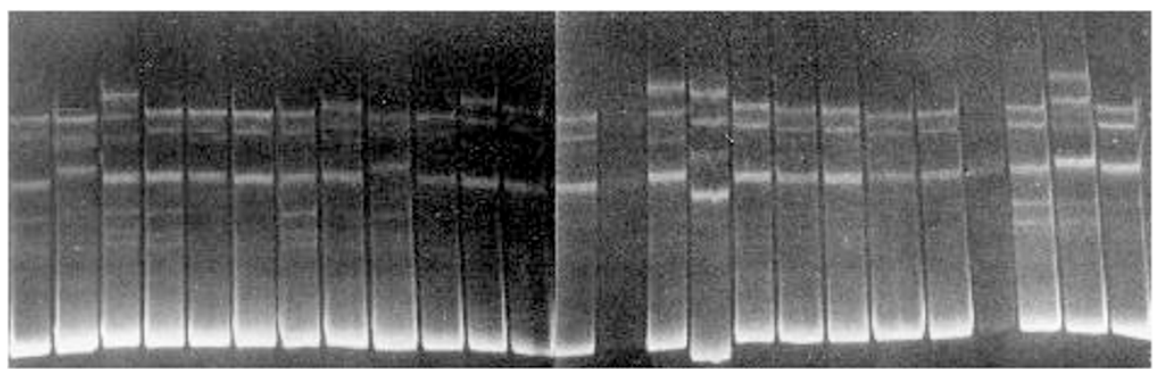

Figure 1. The SSCP patterns of HBV DNA of a core region amplified by PCR from 25 hepatitis $B$ patients. The number represents each chronic hepatitis $B$ patient listed in Table 2 (patient 1 to 25). The extracted DNA from serum of 25 chronic hepatitis $B$ patients was subjected to $P C R$ for amplification of the conserved core region of HBV DNA. For SSCP analysis, $20 \mu$ l of PCR products were denatured with $7 \mu$ l of alkaline solution and $15 \mu \mathrm{l}$ of denaturing loading buffer. After heating at $95^{\circ} \mathrm{C}$ for $5 \mathrm{~min}$, each sample was subjected to gel electrophoresis by $8 \%$ nondenaturing polyacrylamide gel and SSCP analysis was performed as described in 'Materials and Methods'.

\section{Sequence analysis of HBV DNA core region}

To further characterize HBV mutants found in a single chronic hepatitis B patient with anti-HBe $(+)$ (patient 3 in Table 2), we determined DNA sequences (Figure 3). These results confirmed our SSCP findings that many HBV mutants coexist in a single patient's serum. At present, we do not know how these multiple mutants were generated. HBV mutants may arise due to selective pressure during infection. or several HBV mutants may simultaneously co-infect a patient. The well characterized $\mathrm{HBV}$ mutant with mutation in the precore region (nucleotide 1896) which is unable to express $\mathrm{HBeAg}$ was not found in our patient. However, among HBV mutants which were confirmed by DNA sequence analysis, we found one single base-pair deletion mutant (Figure 4). Actually, this deletion mutant was shown in SSCP where double stranded DNA band of this mutant migrated faster than those in other lanes (lane 5 in Figure 2). This deletion mutant is interesting because deletion site is located in the open reading frame of core region, thus encoding a completely different or nonfunctional protein. This mutant is defined by a defective interfering (DI) particle (Huang et al., 1987). At present, there is no information of whether this DI particle with single base pair deletion is able to replicate at the expense of wild type HBV like other DI particles found in almost every other virus groups (Okamoto et al., 1993). Also, there is no information of whether this DI particle interrupts host immune respon-ses against HBV. Since some of HBV mutants have been reported to escape immune responses (Koziol et al., 1976; Swenson et al., 1983), the further examinations of HBV mutants including DI particles will provide us with the clues about the

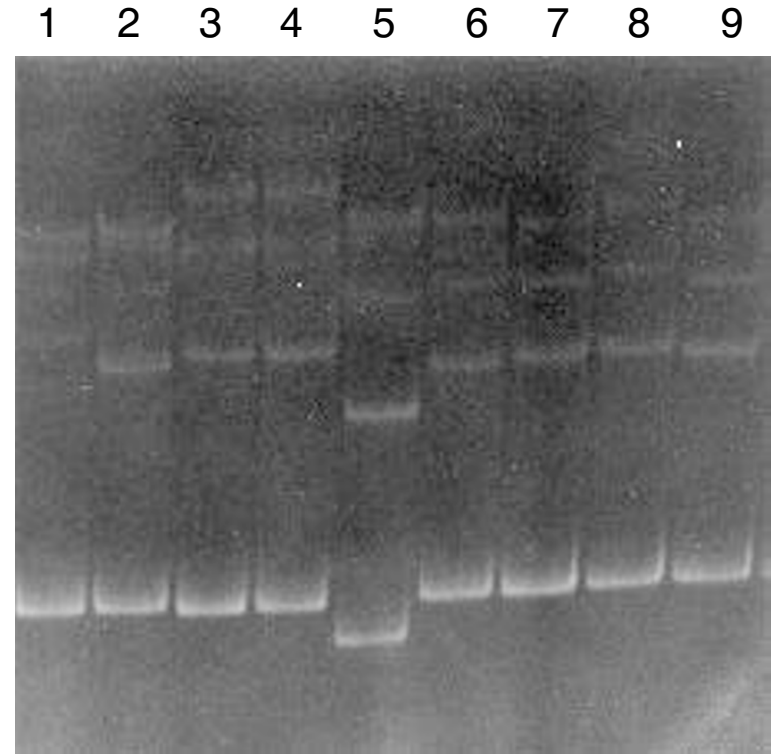

Figure 2. The SSCP patterns of HBV DNA of a core region reamplified by PCR from a single patient. The PCR products amplified from a single patient (patient 3 in Table 2) were ligated into pGEM-T vector, which was transformed into $E$. coli. HBV DNA was reamplified from 40 colonies, and then screened by SSCP analysis. In this result, the SSCP patterns of HBV DNA isolated from only 9 colonies are demonstrated.

immune escape phenomena of HBV occurring in chronic hepatitis $B$ patients.

\section{SSCP analysis of whole HBV genomic area in chronic hepatitis $B$ patients}

Since we found that heterogeneous mutant populations in core region coexisted in a single or multiple hepatitis $B$ patients, we next determined whether HBV mutants were found in whole HBV genomic area. To do these analyses, we amplified whole HBV genomic DNA from two hepatitis B patients (patient 26, 27 in Table 2) using 15 different primer sets (Table 1) and performed SSCP. The results clearly showed that HBV mutants arose in whole region of HBV genome (Figure 5). However, susceptibility to mutation seems to be different depending 

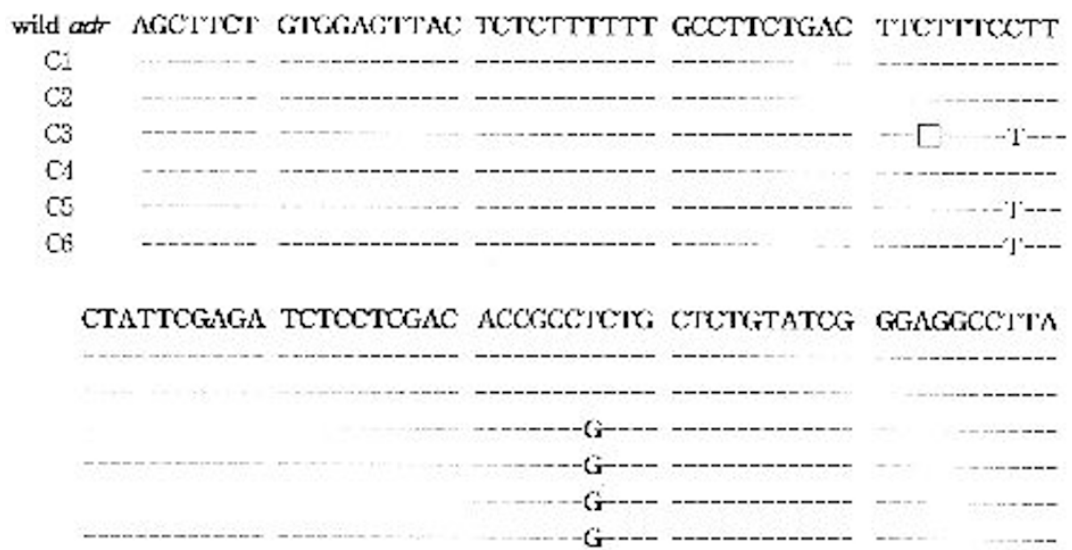

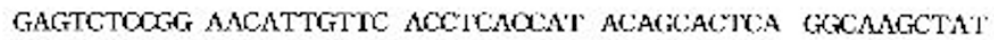

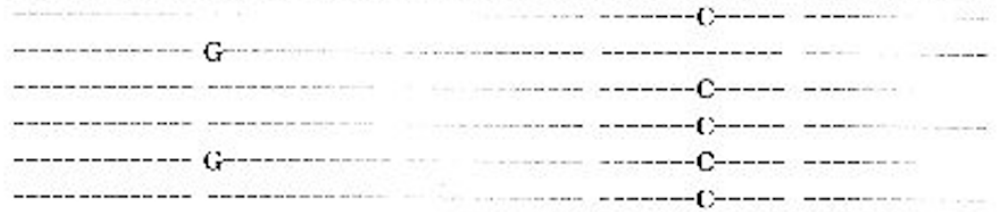

COTYTYTTXG GGTGAGTTGA TGAATTTGGC CACCIGGGIX; GGAAGTAATI

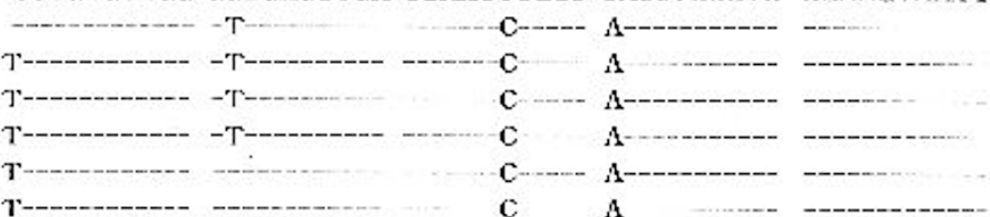

Figure 3. Comparison of nucleotide sequences of precore and core regions of wild adr type and mutants isolated from a single patient. Plasmids containing HBV PCR products amplified from a single patient (patient 3 in Table 2) were isolated from each of 6 bacterial colonies (C1-C6), and their DNA sequences were lined up with that of wild adr type. The mutated nucleotides are demonstrated in letters. The empty square $(\square)$ represents a deleted nucleotide found in DI particle.

\section{deletion mutant wild type}

\section{$\begin{array}{lllllllllllllllllll} & \mathbf{G} & \mathbf{A} & \mathbf{T} & \mathbf{C} & \mathbf{G} & \mathbf{A} & \mathbf{T} & \mathbf{C}\end{array}$}

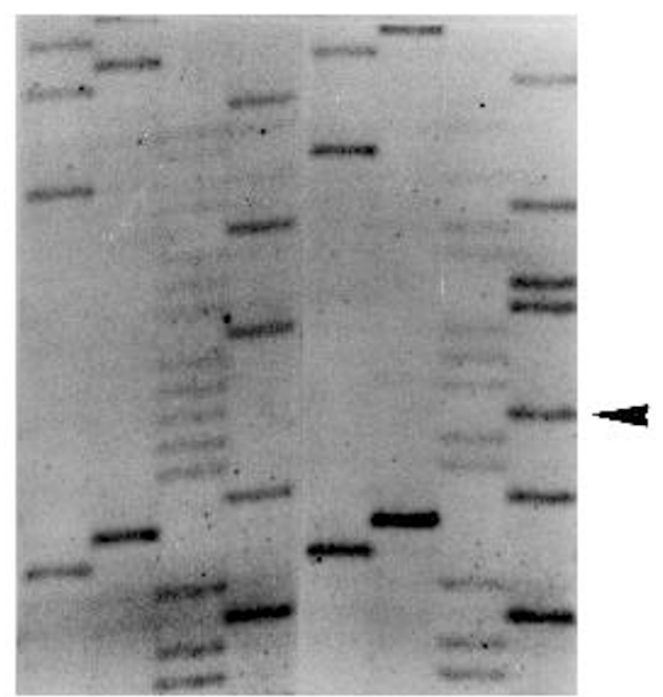

Figure 4. The nucleotide sequence of defective interfering (DI) particle. This DI particle (left panel) does not contain cytosine residue which is indicated by an arrow in a wild adr type. on the genomic area because some lanes (S6, S7, X1, $\mathrm{X} 2$ and $\mathrm{C} 2$ ) have more bands than the other lanes. The result also shows different DNA band patterns for each patient, suggesting that the different HBV mutants exist in two patients

\section{Sequence analysis of surface antigen region}

HBsAg carries a number of antigenic determinants, which are classified into two categories. One is a common ' $a$ ' determinant and the other is subtypic mutually-exclusive ' $d$ ' and ' $y$ ' or ' $w$ ' and ' $r$ ' determinant. As a result, the four major subtypes are created, i.e., $a d w$, adr, ayw and ayr (Ohnuma et al., 1990). To study the HBV mutants in surface antigen region, we analyzed HBV DNA sequence of Korean hepatitis B patients. After PCR-SSCP analysis, E. coli was transformed with HBV DNA samples of two patients in Figure 5 (patient 26, 27 in Table 2), and then eight colonies were sequenced within the $S$ gene. The first three colonies (colony S1-S3) are from patient 26 with anti-HBe (+) and the other five clones (clone S4-S8) are from patient 27 with $\mathrm{HBeAg}(+)$. In Figure 6, DNA sequence of HBV mutants found in these patients was compared with wild-type HBV subtype adr. An Arg-145 variant (Moriyama et al., 1991; Fuji et al., 1992), a well 


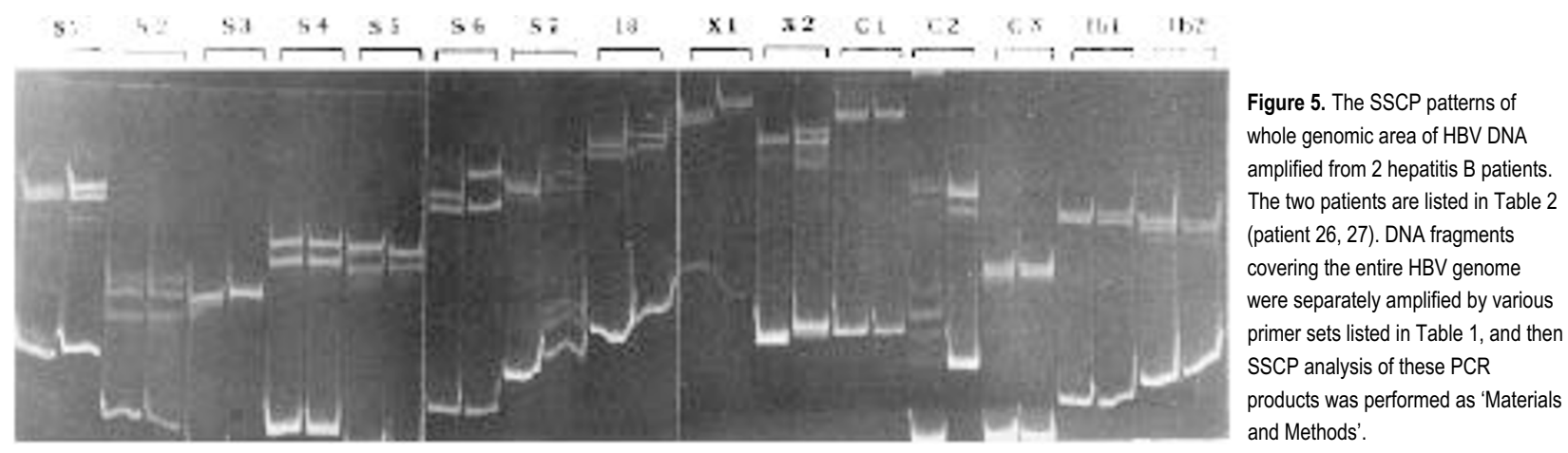

30

]6

si]

$\therefore$

53

$\$ 4$

S5

Sij

Si

St8

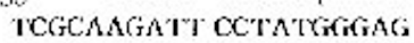

$82--\cdots---1$

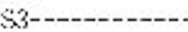

Si:--...-...-

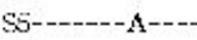

S6….......

$\mathrm{S}$ - - - - $\mathrm{A}--$

S8.....................

TTACTAGTGC CATGGTATTG

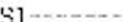

४⿻-1

:

:

:

57--------- ----------

CCACorive

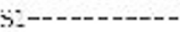

:i2---------

S3--------

S1---------

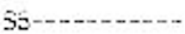

S6-------- -

$5 ?$

$58-1-2 .-1$
66

CTIGININICC CATCCXATCA

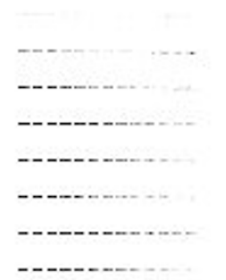

Tricicerteaci tecertTteto
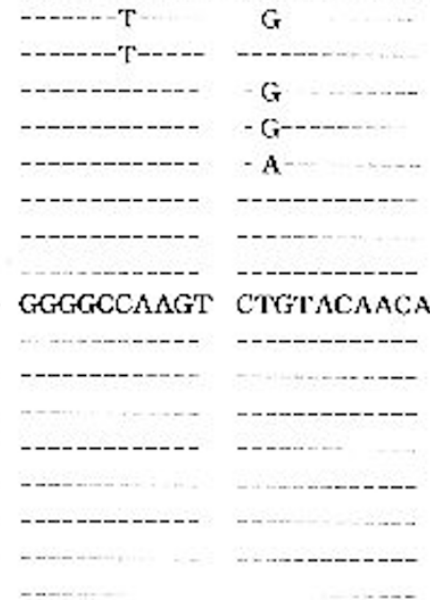

- $\mathrm{G}-\cdots+\cdots$

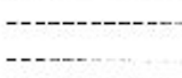

$19 \overline{3}$

TCCTGGGCT\%

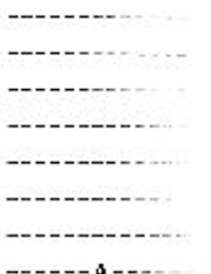

$-\cdots---1-\cdots$

CIGGCITAGT
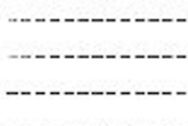

- - -
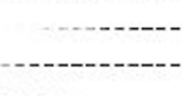

GicictTTCCC

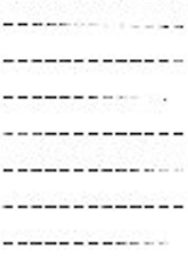

Figure 6. Comparison of nucleotide sequences of $S$ region of wild adr type and mutants isolated from two patients. Plasmids containing HBV PCR products amplified from two patients were isolated (patient 26, 27 in Table 2). The first three clones (S1-S3) were from patient 26 and the second five clones (S4-S8) were from patient 27. Their DNA sequences were lined up with those of wild adr type, and the mutated nucleotides are demonstrated in letters. characterized immune escape mutant, which shows altered antigenicity due to mutation in ' $a$ ' determinant (amino acids 124-147) was not present in our two patients. However, we found a point mutation leading to stop codon (TGG to TAG) at nucleotide 495 (codon 156) in colony S8. The nonsense mutation at this position of surface region (patient 27 ) was not previously reported. In addition, two serological subtypes were observed in this patient. The nucleotide 507 (codon 160) was either G (Arg-160; adw type) in clones S4, S8 or A (Lys-160; adr type) in clones S5-S7. At present, we do not know how two different sub-types coexist in this patient. It is possible that an HBV mutant with $\mathrm{G}$ to A point mutation at nucleotide 507 occurred in this patient resulting in 
Lys-160 and subtypic change from adr to adw; such a mutant may have survived its predecessor (adr) owing to immune pressure exerted by antibodies to the ' $r$ ' determinant. Another possibility is that this patient was infected with two HBV strains of different subtypes ( $a d r$ and $a d w)$. Okamoto et al. reported that a single amino acid substitution by site-directed mutagenesis at codon 160 was responsible for the $r / w$ allelic determinants in the $S$ gene product (Okamoto et al., 1987).

In conclusion, our results show that the diverse hetero-geneous HBV mutants including DI particles exist in Korean chronic hepatitis B patients. At present, it is difficult to establish a certain relationship between a given mutation and its biological effect since most individuals were infected by more than one variant. Further studies on these diverse mutant populations will help us to ultimately understand this relationship and possibly the nature of hepatic disorder caused by HBV infection.

\section{Acknowledgement}

This study was partially supported by the research funds from the Korea Research Foundation, the Basic Medical Research Promotion Fund (BM 97-33) from the Ministry of Education, Republic of Korea.

\section{References}

Ackrill, A. M., Naoumov, N. V., Eddleston, A. L. and Williams, R. (1993) Special detections in the hepatitis $B$ virus core open reading frame in patients with chronic active hepatitis. J. Med. Virol. 41: 165-169

Alexopoulou, A., Karayiannia, P., Hadziyannis, S. J., Aiba, N. and Thomas, H. C. (1997) Emergence and selection of HBV variants in an anti-HBe positive patient persistently infected with quasi-species. J. Hepat. 26: 748-753

Blum, H. E. (1993) Hepatitis B virus: significance of naturally occurring mutants. Intervirology 35: 40-50

Blum, H. E., Galun, E., Liang, T. J., Weizasker, F. and Wands, J. (1991) Naturally occurring missense mutation in the polymerase gene terminating hepatitis $B$ virus replication J. Virol. 65: 1836-1842

Carman, W. F., Hadziyannis, S., McGarvey, M. J., Jacyna, M. R., Karayiannis, P., Makris, A and Thomas, H. C. (1989) Mutation preventing formation of hepatitis B e-antigen in patients with chronic hepatitis B infection. Lancet 2: 588-591

Carman, W. F., Thomas, H. and Esteban, D. (1993) Viral genetic variation: hepatitis B virus as a clinical example. Lancet 341: 349-352

Chi, S. G., deVere White, R. W., Meyers, F. J., Siders, D. B., Lee, F. and Gumerlock, P. H. (1994) p53 in prostate cancer: frequent expressed transition mutations. J. Natl Cancer Inst. 86: 926-933

Chiou, H.-L., Lee, T.-S., Kuo, J., Mau, Y.-C. and Ho, M.-S. (1997) Altered antigenicity of 'a' determinant variants of hepatitis B virus. J. Gen. Virol. 78: 2639-2745

Chisari, F. V. and Ferrari, C. (1995) Hepatitis B virus immunopathogenesis. Ann. Rev. Immunol. 13: 3358-3368

Fiordalisi, G., Cariani, E., Mantero, G., Zanetti, A., Tanzi, E., Chiaramonte, M. and Primi, D. (1990) High genomic variability in the pre-C region of hepatitis B virus in anti-HBe,
HBV DNA positive chronic hepatitis. J. Med. Virol. 31: 297-300

Fuji, H., Moriyama, K., Sakamoto, N., Knodo, T., Yasuda, K., Hiraizumi, Y., Yamazaki, M., Sakaki, Y., Okochi, K. and Nakajima, E. (1992) Gly 145 to Arg substitution in HBs antigen of immune escape mutant of hepatitis B virus. Biochem. Biophy. Res. Comm. 184: $1152-1157$

Hasegawa, K., Huang, J. K., Rogers, S. A., Blum, H. E. and Liang, T. J. (1994) Enhanced replication of a hepatitis $B$ virus mutant associated with an epidemic of fulminant hepatitis. J. Virol. 68: 1651-1659

Hawkins, A. E., Gilson, R. J. C., Gilbert, N., Wreghitt, T. G., Gray, J. J. Ahlers-de Boer, I., Tedder, R. S. and Alexander, J. M. (1996) Hepatitis B virus mutations associated with infection after liver infection. J. Hepatol. 24: 8-14

Huang, S. N (1987) The Role of Defective Interfering (DI) Particles in viral infection. In The molecular basis of viral replication. (Perez Bercoff, R. ed.), pp. 191-194, Plenum Press, New York

Kaneko, S., Miller, R. H., Di Bisceglie, A. M., Feinstone, S. M., Hoofnagle, J. H. and Purcell, R. H. (1990) Detection of hepatitis B virus DNA in serum by polymerase chain reaction: application for clinical diagnosis. Gastro-enterology 99: 799-804

Karthigesu, V. D., Allison, M. C., Fortuin, M., Mendy, M., Whittle, H. C. and Howard, C. R. (1994) A novel hepatitis B virus variant in the sera of immunized children. J. Gen. Virol. 75: 443-448

Keum, W. K., Park, C. E., Lee, J. H., Khil, L.-Y., Kang, I., Kim, S. S., Jung, J. C., Oh, S. M., Woo, H. J., Lee, J. H., Kim, Y. C., Yoon, Y., Choi, J. W. and Ha, J. (1997) Primers determine the sensitivity of PCR-mediated hepatitis $B$ virus detection and pretreatment of PCR mixture with 8-methoxypsoralen eliminates false-positive results. Mol. Cells. 7: 244-250

Koziol, D. E., Alter, H. J., Kirchner, J. P. and Holland, P. V. (1996) The development of HBsAg-positive hepatitis despite the previous existence of antibody to HBsAg. J. Immunol. 117: 2260-2262

Miska, S., Gunther, S. and Will, H. (1994) Biology and clinical features of hepatitis B virus P-, S- and X-gene variants. Hepatologia Clinica 2: 161-180

Moriyama, K., Nakajima, E., Hohjoh, H., Asayama, R. and Okochi, K. (1991) Immunoselected hepatitis B mutant. Lancet 337: 125

Nordenfelt, E. and Kjellen, L. (1995) Dane particles, DNA polymerase and e-antigen in two different categories of hepatitis B antigen carriers. Intervirology 5: 225-232

Okamoto, H., Wang, Y., Tanaka, T., Machida, A., Miyakawa, Y. and Mayumi, M. (1993) Trans-complementation among naturally occurring deletion mutations of hepatitis $B$ virus and integrated viral DNA for the production of viral particles with mutant genomes in hepatoma cell lines. J. Gen. Virol. 74: 407-414

Okamoto, H., Imai, M., Miyakawa, Y. and Mayumi, M. (1987) Site-directed mutagenesis of hepatitis $B$ surface antigen sequence at codon 160 from arginine to lysine for conversion of subtypic determinant from $r$ to w. Biochem. Biophy. Res. Comm. 148: 500-504

Ohnuma, H., Takai, E., Machida, A., Tsuda, F., Okamoto, H., Tanaka, T., Naito, M., Munekata, E., Miki, K., Miyakawa, Y. and Mayumi, M. (1990) Synthetic oligopeptides bearing a common or subtypic determinant of hepatitis B surface antigen. J. Immunol. 145: $2265-2271$

Saunders, K. A., Madewell, B. R., Oreffo, V. I., Kraegel, S. A., Gumerlock, P. H. (1992) Nucleotide sequence of caine c-N-ras: codons 1 to 71. Am J. Vet. Res. 53: 600-603

Summers, J., Mason, W. S. (1982) Replication of the genome of a hepatitis-like virus by reverse transcription of an RNA intermediate. Cell 29: 403-415

Swenson, P. D., Escobar, M. R., Carithers, R. L Jr. and Soboeski, T. J III. (1983) Failure of preexisting antibody against hepatitis $B$ surface antigen to prevent subsequent hepatitis B infection. J. Clin. Microbiol. 18: 305-309

Ulrich, P. P., Bhat, R. A., Kelly, I., Brunetto, M. R., Bonino, F. and Vyas, G. N. (1990) A precore-defective mutant of hepatitis $B$ virus associated with e antigen-negative chronic liver disease. J Med. Virol 32: 109-18 
Wallace, L. A. and Carman, W. F. (1994) Clinical implications of hepatitis B virus envelope protein variation. Int. J. Clin. Lab. Res. 24: 80-85

Will, H., Reiser, W., Weimer, T., Pfaff, E., Buescher, R., Sprengel, R., Cattaneo, R. and Schaller, H. (1987) Replication strategy of human hepatitis B virus. J. Virol. 61: 904-911 